International Review of Research in Open and Distributed Learning Volume 17, Number 1

January - 2016

\title{
A Cognitive Style Perspective to Handheld Devices: Customization vs. Personalization
}

Chen-Wei Hsieh and Sherry Y. Chen

National Central University, Jhongli, Taiwan

\begin{abstract}
Handheld devices are widely applied to support open and distributed learning, where students are diverse. On the other hand, customization and personalization can be applied to accommodate students' diversities. However, paucity of research compares the effects of customization and personalization in the context of handheld devices. To this end, a customized digital learning system (CDLS) and personalized digital learning system (PDLS) were implemented with the handheld devices and they tailored to the needs of different cognitive style groups. Furthermore, we conducted two empirical studies to examine the effects of cognitive styles on the use of the CDLS and PDLS. More specifically, Study 1 identified the preferences of each cognitive style group while Study 2 investigated how students with different cognitive styles react to the CDLS and the PDLS. The results from these two studies showed that student with the CDLS and those with the PDLS obtained similar task scores and post-test scores, regardless of their cognitive styles. However, cognitive styles affected the efficiency of completing tasks and perceptions for customization and personalization.
\end{abstract}

Keywords: customization, personalization, handheld devices, cognitive styles 


\section{Introduction}

Handheld devices are becoming popular companions that support our daily life. Due to increased storage and improved speed, handheld devices can provide multiple functions, such as tour guides, search instruments, and entertainment tools (Myers \& Beigl, 2003). As claimed by Attewell (2005), handheld devices become an inseparable part of the "digital life" for many people around the world. This is owing to the fact that handheld devices have small screens (Jonsson, Nass, \& Lee, 2004) so they can be used at any time and any places. Furthermore, handheld devices permit the delivery of a range of multimedia material, such as audio, graphics, and video. In spite of such benefits, handheld devices are not expensive when compared with other types of computers (Allan, Carbonaro, \& Buck, 2006). Accordingly, handheld devices are increasingly being used in educational settings (Cheung \& Hew, 2009). In particular, handheld devices are widely applied to undertake open and distributed learning (Rosli, Ismail, Idrus, \& Ziden, 2010). Thus, it is believed that handheld devices offer a spectrum of educational opportunities (Churchill \& Hedberg, 2008). Due to such significance, an increasing number of students use handheld devices for their studies. In other words, handheld devices are widespread and face students with diverse backgrounds, in terms of their knowledge, skills, and needs (Chen \& Macredie, 2010).

Therefore, human factors are essential issues. Among various human factors, cognitive styles affect an individual preferred and habitual approach to organizing and representing information (Riding \& Rayner, 1998). Several dimensions of cognitive styles exist, including Holist-Serialist (Pask, 1976), WholistAnalytical (Riding, 1991), and Field-Dependence/ Field-Independence (Witkin, Moore, Goodenough,\& Cox, 1977). Among such dimensions, early research mainly emphasized on Witkin's Field-Dependence/ Field-Independence (e.g., Chen \& Macredie, 2002) while recent studies shifted to examine Pask's Holism/Serialism (e.g., Clewley, Chen \& Liu, 2010). These two dimensions of cognitive styles have conceptual links (Chen \& Macredie, 2002). More specifically, there are some similarities between Field Dependent users and Holists and between Field Independent users and Serialists. Clewley, Chen and Liu (2010) analyzed the relationships between Field Dependence/Independence and Holism/Serialism. Their results indicated that both Field Dependent users and Holists prefer to have lots of options that are available to them because they prefer to take a global approach. Conversely, Field Independent users and Serialists preferred that only relevant options would be shown. In other words, Field Dependent users and Holists share similar preferences while there are some similarities Field Independent users and Serialists.

Such relationships reveal that Holist strategies are characterized by a global approach to problems and tend to use a simultaneous approach to the various parts of a task while Serialist strategies are more local and are directed at only one aspect of the problem at one time (Pask, 1979). Additionally, Jonassen and Grabowski (1993) describe Holists as preferring to process information in a "whole-to-part" sequence. In contrast, Serialists are described as preferring a "part-to whole" processing of information. A detailed comparison of Holists and Serialists is described in Table 1.

Table 1. 
Differences between Holists and Serialists (Pask, 1976)

\begin{tabular}{lll}
\hline \multicolumn{1}{c}{ Holists } & \multicolumn{1}{c}{ Serialists } \\
\hline$\Gamma \quad \begin{array}{l}\text { Take a global approach and create } \\
\text { conceptual links between objects } \\
\text { early on. }\end{array}$ & $\begin{array}{l}\text { Take an analytical approach, examining } \\
\text { individual topics before forming } \\
\text { conceptual links. }\end{array}$ \\
$\begin{array}{l}\text { Is able to move between theory and } \\
\text { real world examples from the } \\
\text { beginning. }\end{array}$ & $\begin{array}{l}\text { Analyze theory or real world examples } \\
\text { separately, only joining together if } \\
\text { necessary. }\end{array}$ \\
$\begin{array}{l}\text { Broad focus: prefer to have more than } \\
\text { one task on the go at the same time. }\end{array}$ & $\begin{array}{l}\text { Narrow focus: prefer to complete one } \\
\text { task before moving onto the next. }\end{array}$ \\
\hline
\end{tabular}

As shown in Table 1, Holists and Serialists do have different characteristics. Such different characteristics affect how they use technology-based learning tools. For instance, Clewley, Chen and Liu (2010) examined users' preferences in using search engines. They found Holists preferred to have multiple options but Serialists did not demonstrate such a preference. Later on, they conducted another study, the results of which indicated that Serialists and Holists had different preferences for their navigational styles. The former preferred to follow a linear pattern by looking at the subject content step-by step with back/forward buttons. Conversely, the latter tended to take a non-linear pattern by "jumping” between different levels of subject contents with hypertext links (Clewley, Chen \& Liu, 2011).

Because of such differences between Holists and Serialists, recent studies attempted to accommodate their different preferences with personalization, which automatically recommends relevant course materials according to each learner's needs and interests (Tan, Guo, \& Li, 2008). For instance, Mampadi, , Chen, Ghinea, \& Chen (2011) developed a personalized learning system to tailor to the needs of Holists and Serialists. Their results demonstrated that this personalized learning system could improve students' learning performance and perceptions. Their findings suggest that personalization is an effective approach to match with the needs of different cognitive style groups. This is because personalization automatically adapts to users' needs based on observed behaviors. Amazon.com, which is a good example with personalization, recommends products according users' past purchasing records (Maglio, Barrett, Campbell \& Selker, 2000). In addition to the recommendation of products, personalization was also applied for other applications, such as culture resources (Gena, Cena, Vernero, \& Grillo, 2013) and programming learning (Hsieh, Lee, \& Su, 2013).

Further to personalization, the other approach to tailor to the needs of each individual is customization. The differences between personalization and customization lie within the fact that the former uses adaptivity to tailor content, structure and/or presentation to each individual automatically while the latter provides individuals with adaptability to modify the content presentation, format layouts, and navigation facilities by themselves (Treiblmaier, Madlberger, Knotzer \& Pollach, 2004). Customization refers to the degree to which a technology, good, or service can be created, selected, or changed to comply with user preferences (Teng, 2010). In a customized environment, users are generally provided with a menu, with which they can activate or deactivate functionalities offered by the environment (Frias- 
Martinez, Chen, \& Liu, 2009). Kelly et al. (2009) introduced a framework for Web adaptability, which was applied to support the needs of users with specific disabilities. Finally, they concluded that customization provided users with greater freedom to facilitate individual accessibility in an open Web environment. Teng (2010) examined how customization affected online gaming and found that customization could enhance immersion satisfaction and gamer loyalty and recommended that software should allow users to change the configurations, visual, sound effects, and software interface.

In brief, both customization and personalization are helpful. Accordingly, various web-based applications, such as digital library and e-commerce, provided customization and personalization in the past decade. However, these two approaches are very different. Kobsa, Koenemann, and Pohl (2001), one of the leading teams in this area, identified the differences between customization and personalization and indicated that customization involves initiation, proposal, selection, and production whereas personalization involves individualized content, structure, and presentation. Customization is user driven while personalization is system driven. In other words, these two approaches differ with respect to who takes the initiative (Kay, 2001). The former are user-controlled while the latter are system-controlled. Giving the control to the users can reduce the effect of incorrect adaptation (Finlater \& McGrenere, 2004). However, the cost of the increased controllability is that users need to put additional effort. Accordingly, both customization and personalization have different advantages and disadvantages.

Thus, researchers attempted to compare the effectiveness of these two approaches. For example, FriasMartinez, Chen, and Liu, (2009) developed a digital library, which included two versions, i.e., personalized version and customized version, to accommodate the needs of users with different cognitive styles. The results showed that cognitive styles had great effects on users' responses to personalization and customization. Field Dependent users reacted more positively to the personalized version while Field Independent users had more positive perception to the customized version. Such a comparison provided concrete evidence to illustrate how different cognitive style groups reacted to personalization and customization. By doing so, designers can understand how to choose a right approach to accommodate the needs of different cognitive style groups. However, paucity of research compares customization and personalization in the context of handheld devices from a cognitive style perspective.

In other words, it is necessary to incorporate customization and personalization into handheld devices and compare learners' reactions from a cognitive style aspect. To this end, a Customized Digital Learning System (CDLS) and Personalized Digital Learning System (PDLS), which were applied to deliver lectures for an open and distributed learning course, were implemented in Study 1 and Study 2, respectively. In Study 1, the CDLS was applied to investigate the effects of cognitive styles on learners' preferences, which were employed to develop the PDLS in Study 2. Additionally, we investigated the influences of cognitive styles on students' reactions to the CDLS and the PDLS in Study 2. Study 1 and Study 2 address different concerns but the ultimate aim of our work is to find an answer to the research question -- how different cognitive style groups react to customization and personalization in the context of handheld devices. The answer to this research question can contribute a complete understanding of how to make the best use of customization and personalization to support digital learning in the context of handheld devices. 


\section{Methodology Design}

Two empirical studies were conducted to identify how different cognitive style groups react to the CDLS and PDLS implemented with the handheld devices. The participants of these two empirical studies were selected by convenience sampling, which offers convenient accessibility and proximity (Powell, 1997). More specifically, we selected the participants from students who studied in the National Central University in Taiwan, where the authors of this paper worked. The research instruments used for these two studies included the Study Preferences Questionnaire (SPQ), a task sheet, pre-test, post-test, and questionnaires, which are described in subsections below.

\section{Study Preferences Questionnaire}

Among various instruments, the Study Preferences Questionnaire (SPQ) can do a quick and easy measure of Holist and Serialist biases. Furthermore, it has been used in several studies (e.g, Clewley, Chen and Liu, 2011) and showed adequate reliability ( $=0.67)$ in past research (MampadiChen, Ghinea \& Chen, 2011). Thus, the SPQ was applied to identify Holists and Serialists in this research. The criteria suggested by Ford (1985) were applied to identify Holists and Serialists in this research. More specifically, students were provided with two sets of 17 statements and they were asked to choose the statements that they agreed or to indicate no preferences. Based on their choices, if users agreed with over half of the statements related to Holists, they were identified as Holists. Conversely, they were considered as Serialists.

\section{Task Sheet}

When interacting with the CDLS or PDLS, the participants were given a task sheet, which described the tasks that learners needed to perform. These tasks were used to assess students' learning performance. The tasks were 15 factual questions which covered various topics presented in the CDLS/PDLS so that the topic bias could be reduced. Each question focused on a single concept and had only one right answer. In other words, the participants needed to locate the answer to each question with the CDLS and PDLS. Two hours were allocated for each student to complete the tasks. The starting time and the ending time for each student were recorded. By doing so, the amount of time spent for completing the tasks could be applied to measure the participants' learning performance.

\section{Pre-test and Post-test}

The pre-test and post-test were conducted to assess the participants' levels of knowledge of the subject domain both before and after using the CDLS or PDLS. The pre-test gave an objective assessment of the participants' prior knowledge of the subject domain while the post-test was designed to assess how much they have learnt. Both of the pre-test and post-test were presented in a computer-based format and included 20 multiple-choice questions. Each question included three different answers and an "I don't know" option but there was only one right answer.

\section{Questionnaire}


Questionnaires provide a means of examining students' reactions quickly and easily (Kinshuk, 1996). This study specifically examines how learners' cognitive styles influence their reactions to the CDLS or PDLS so existing questionnaires may not be suitable. Therefore, a specific questionnaire, which was designed for this research, was divided into two parts. The first part focused on background information, such as age, gender, academic background, the frequencies of using handheld devices/Internet and the enjoyment of using handheld devices. The second part was committed to realize students' learning experience. All of questions were designed based on five Likert Scale, which consisted of: "strongly agree," "agree," "neutral," "disagree," and "strongly disagree." Students were required to indicate agreement or disagreement with each question that most closely reflected their opinions. To reduce the bias, there was nearly an equal number of positive and negative statements.

\section{Study 1}

\section{Customized Digital Learning System}

The CDLS delivered the lectures of Interaction Design for an open and distributed learning course and provided 10 kinds of tools, which can be broadly divided into two types: reading tools (i.e., Topic, Content, Image, Route, History, Undo, and Redo) and searching tools (i.e., Keyword, Main menu, Alphabetical Index, Next, and Previous). These tools were selected because they served different purposes and are complementary to each other. In addition, learners were allowed to customize the layout and toolbar based on their particular needs. In other words, the CDLS offered flexibility to allow learners to develop their own learning strategies based on their preferences. Figure 1 shows the initial layout of the CDLS where the tools have not been selected while Figure 2 illustrates the final layout of the CDLS where the tools have been selected.

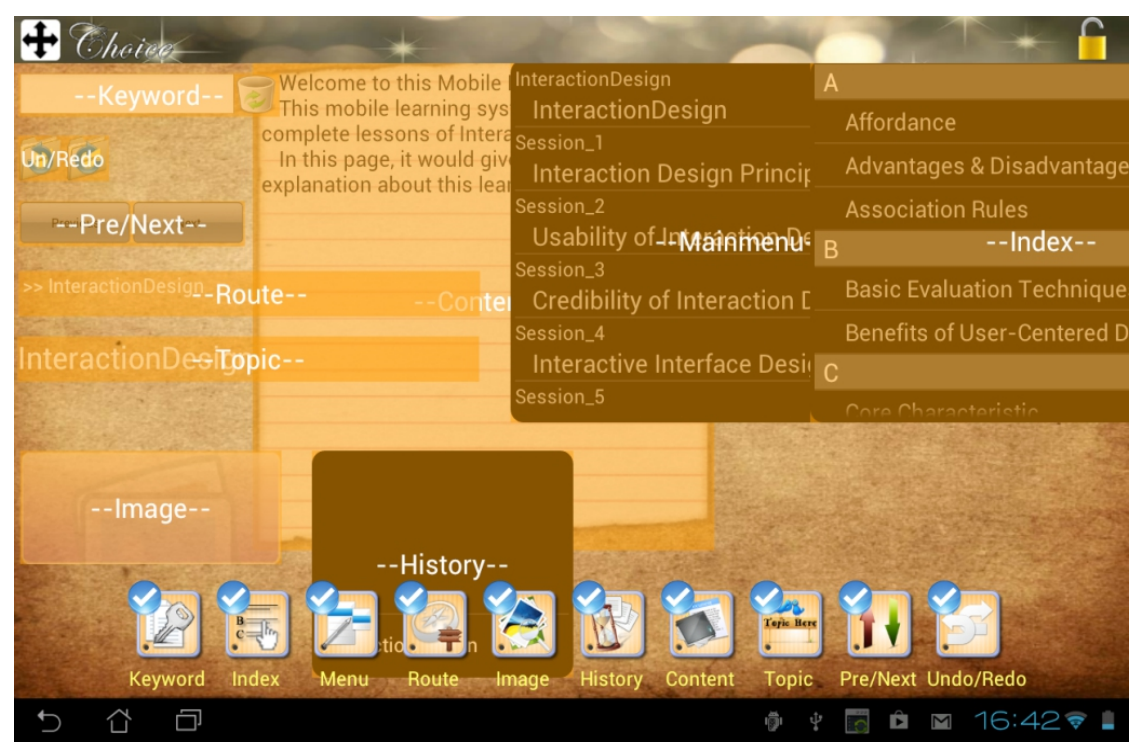

Figure 1. Customized Digital Learning System (Initial Layout) 


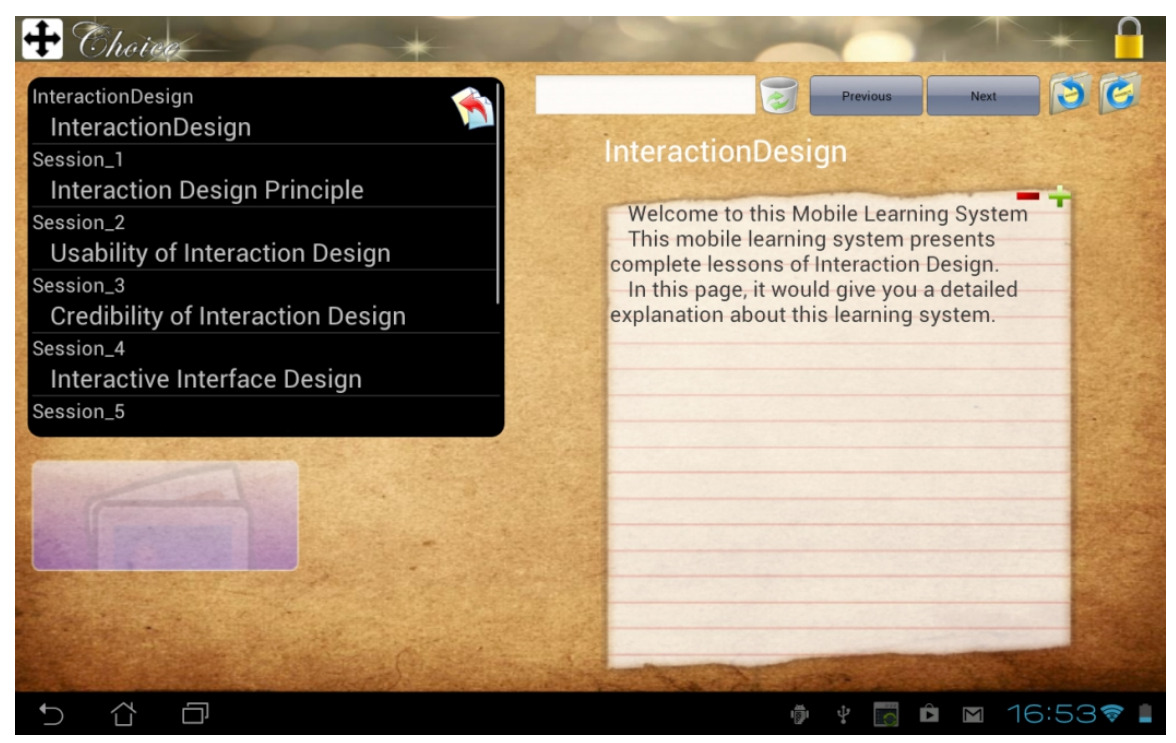

Figure 2. Customized Digital Learning System (Final Layout)

\section{Experimental Procedure}

Among various types of handheld devices, Tablet PCs have the proper size of display screens and keypads so that acceptable readability can be demonstrated. Accordingly, the Tablet PCs were employed to conduct this study, which included 60 participants. All of the participants went through the same procedure, which consisted of five stages. Initially, all of the participants were required to take the SPQ to categorize them as Holists or Serialists. According to the results of the SPQ, there were 34 Holists and 26 Serialists. Subsequently, all of the participants were required to take the pre-test to identify their prior knowledge about the subject content before interacting with the CDLS.

Thereafter, all participants were instructed how to use a Tablet PC and the tools provided by the CDLS. This instruction was meant to minimize the gap between diverse experience that participants possessed in using these instruments. Later on, all participants were required to complete the practical tasks by finding information from the CDLS. Simultaneously, the time that they spent for completing the tasks was recorded in a log file. Then, learners needed to take the post-test, which was used to evaluate their learning performance. Finally, all of the participants filled out the questionnaire to express their perceptions for the CDLS.

\section{Data Analyses}

As shown in our previous work (Frias-Martinez, Chen, Macredie, \& Liu, 2007), data mining, especially clustering, is an effective approach to identify learners' behavior. Thus, clustering was employed in this study. More specifically, the frequency of using each tool and the arrangement of display formats were applied to produce clusters that shared similar learning behavior. Subsequently, the corresponding cognitive styles and learning performance for each cluster were identified. The learning performance was measured based on: (1) the time spent for completing the tasks; (2) task scores; and (3) post-test scores. By doing so, we could identify the cluster that showed the best performance and then discover how 
learners in this cluster behaved.

Among various clustering algorithms, K-means was widely used to analyze students' learning behavior (Chen \& Liu, 2008). A major limitation of using the K-means algorithm is that the number of clusters needs to be predefined. In other words, there is a need to identify the most suitable number of clusters to perform the K-means algorithm. Such an issue can be treated as parameter exploration (De Jong, 1975), which is used to decide the suitable number of clusters. The suitable number of clusters is determined based on not only the smallest distance between the features in a same cluster, but also the largest distance between the features in different clusters. By choosing this suitable number, students in the same cluster share the most similarities while those in the different clusters own the most differences.

\section{Results and Discussions}

The results from the K-means showed that three clusters were produced for Serialists while only two clusters were created for Holists. Table 2 and Table 3 describe the attributes that characterize clusters for Serialists and Holists, respectively. As shown in these two tables, Serialists in Cluster 3 obtained the highest task scores and post-test scores and spent the least amount of time completing the tasks whereas Holists in Cluster 1 obtained the highest task scores and spent the least amount of time completing the tasks. In other words, the best achievers are Serialists in Cluster 3 and Holists in Cluster 1. The subsections below describe the learning behavior of such Serialists and Holists, in term of the use of various tools and the arrangement of display formats.

Table 2

The Trends of Three Clusters for the Serialists

\begin{tabular}{ccccccc}
\hline & \multicolumn{2}{c}{ Task Time } & \multicolumn{2}{c}{ Task Scores } & \multicolumn{2}{c}{ Post-test Scores } \\
\cline { 2 - 6 } Group & $\boldsymbol{M}$ & $\boldsymbol{S D}$ & $\boldsymbol{M}$ & $\boldsymbol{S D}$ & $\boldsymbol{M}$ & $\boldsymbol{S D}$ \\
\hline Cluster 1 & 113.67 & 37.10 & 18.67 & 7.57 & 11.33 & 1.53 \\
Cluster 2 & 82.67 & 15.57 & 17.67 & 7.57 & 13.33 & 3.79 \\
Cluster 3 & 64.71 & 26.17 & 21.29 & 6.63 & 14.29 & 3.15 \\
\hline
\end{tabular}

Table 3.

The Trends of Two Clusters for the Holists

\begin{tabular}{ccccccc}
\hline & \multicolumn{2}{c}{ Task Time } & \multicolumn{2}{c}{ Task Scores } & \multicolumn{2}{c}{ Post-test Scores } \\
\cline { 2 - 7 } Group & $\boldsymbol{M}$ & $\boldsymbol{S D}$ & $\boldsymbol{M}$ & $\boldsymbol{S D}$ & $\boldsymbol{M}$ & $\boldsymbol{S D}$ \\
\hline Cluster 1 & 69.7 & 30.76 & 20.5 & 5.64 & 14.5 & 2.37 \\
Cluster 2 & 73.57 & 21.11 & 18.57 & 5.35 & 14.43 & 2.99 \\
\hline
\end{tabular}


Use of Various Tools. As showed in Figure 3, Serialists mainly used the main menu and the keyword search. The main menu is useful to browse the subject content topic by topic so it can facilitate Serialists to take a sequential approach. On the other hand, the keyword search is helpful to find specific information so it can help Serialists obtain procedural details (Pask, 1976). This finding is consistent with that of Chen and Chang (in press), which indicates that keyword search is suitable for Serialists to find specific details. Conversely, the previous/next buttons were the most favorite tools for Holists (Figure 4). This may be due to the fact that the previous/next buttons can facilitate Holists to undertake non-linear learning. Additionally, the main menu, which allowed learners to locate the information with "topic" based learning, was the second favorite tool for Holists. More specifically, the main menu presents all topics so it is helpful for Holists to see a global picture.

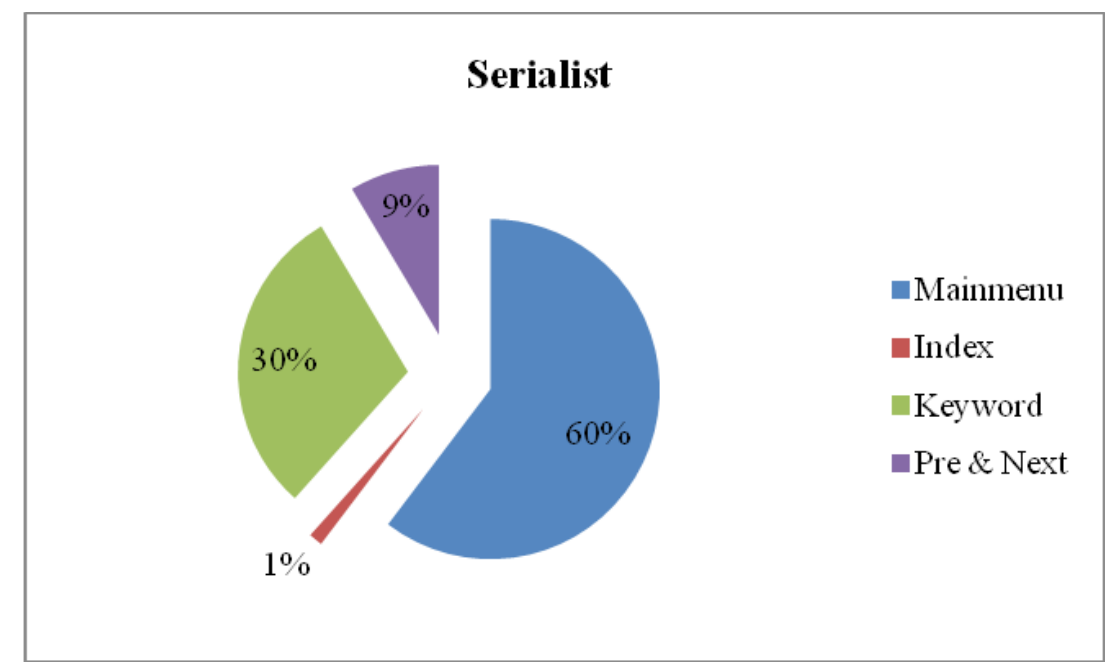

Figure 3. The tools used by Serialists 


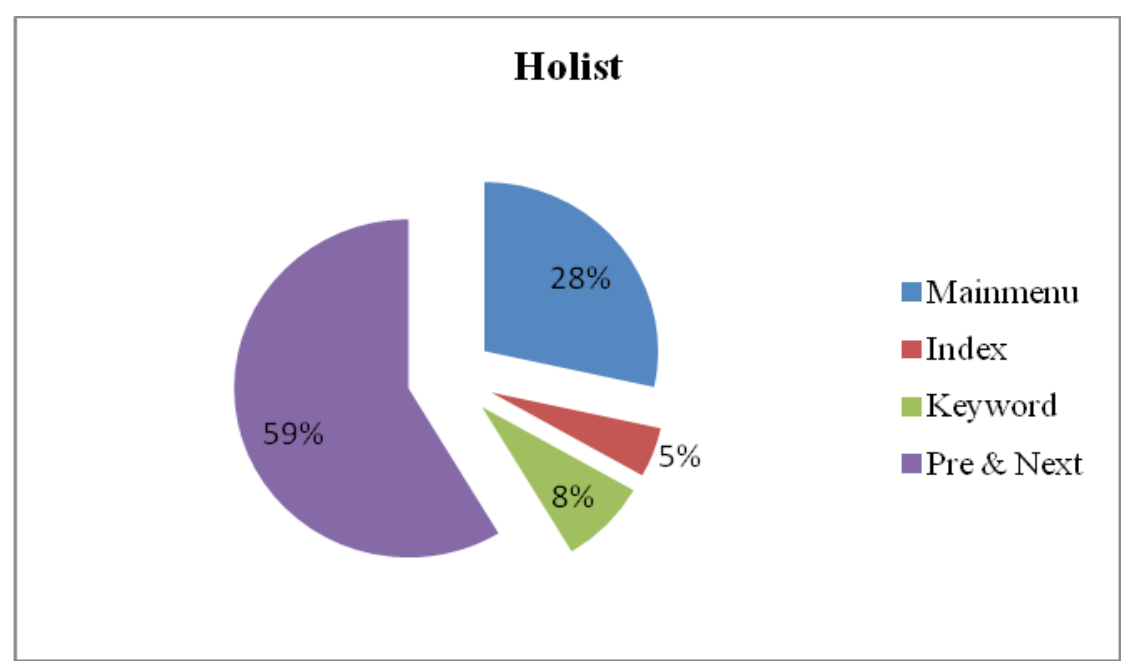

Figure 4. The tools used by Holists

Arrangement of Display Formats. As showed in Figure 5 and Figure 6, Serialists and Holists favored different types of display formats. The results indicate that Serialists tended to put the reading tools on the right side and the searching tools on the left side. Conversely, Holists preferred to put the searching tools on the right side and the reading tools on the left side. More specifically, the difference between these two approaches lies within the fact that the former is a format changed by learners while the latter is a default format originally displayed in the CDLS. In other words, Holists tended to adjust themselves to use an existing format while Serialists attempted to modify the format to match with their needs. This may be due to the fact that Holists are good at re-organizing information so they feel comfortable to adjust themselves to use the existing format.

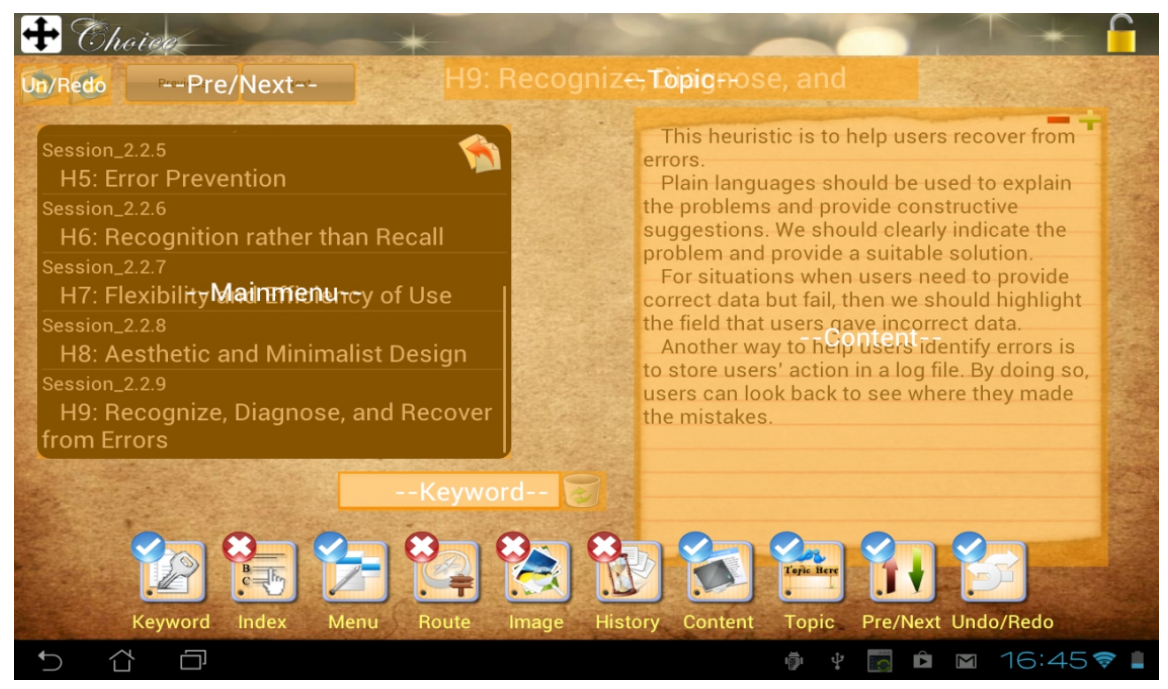

Figure 5. Display Format arranged by Serialists 


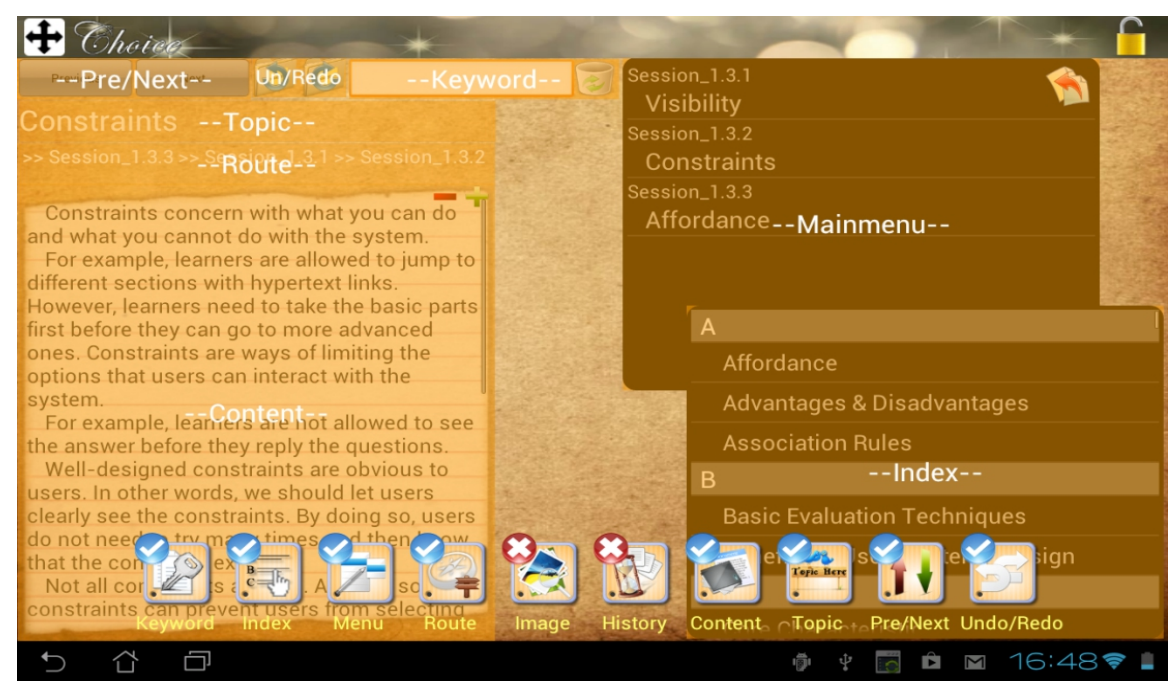

Figure 6. Display Format arranged by Holists

\section{Summary}

This study examined how cognitive styles affected learners' reactions to customized learning materials delivered via the handheld devices. Figure 7 proposes a user model which illustrates the learning behavior of Holists and Serialists. More specifically, Serialists who demonstrated the best learning performance mainly used the main menu and the keyword search. In addition, they tended to put the reading tools on the right side and the searching tools on the left side. On the other hand, Holists who had the best learning performance majorly used the main menu and the previous/next buttons. Moreover, they preferred to put the searching tools on the right side and the reading tools on the left side. Such results were further employed to develop the PDLS in Study 2. 


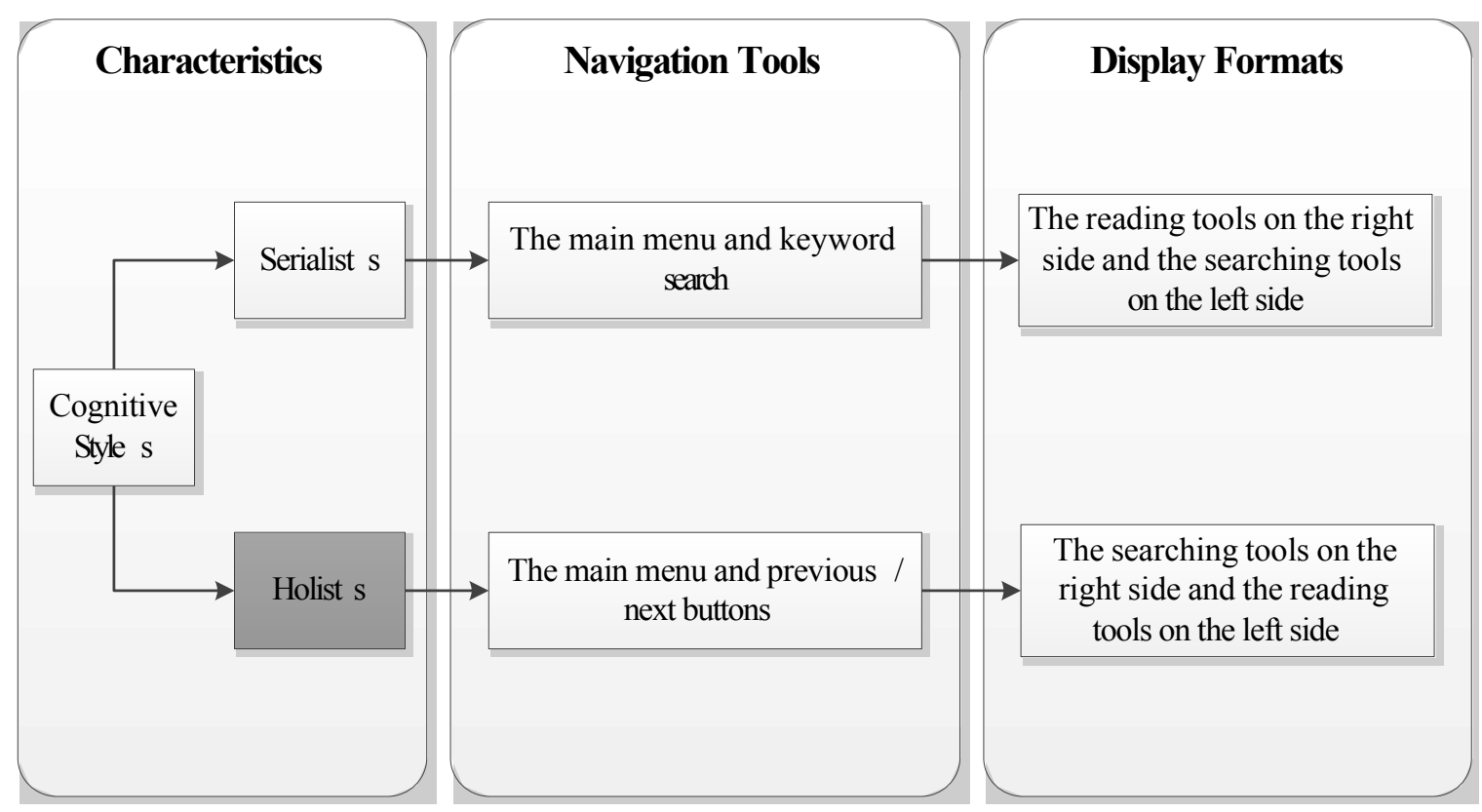

Figure 7. User model

\section{Study 2}

\section{Personalized Digital Learning System}

The user model shown in Figure 7 was further applied to develop the PDLS. Like Study 1, the PDLS was applied to deliver the lectures of Interaction Design for an open and distributed learning course. The PDLS included two versions: Serialist Version and Holist Version. Regarding the former (Figure 8), major searching tools were the main menu and keyword search. Additionally, the reading tools were located on the right side and the searching tools on the left side. Regarding the latter (Figure 9), main searching tools were the main menu and previous/next buttons. Moreover, the reading tools were located on the left side and the searching tools on the right side. The same content was used for both Holist and Serialist Versions without incurring the practice and fatigue effects in this study. 


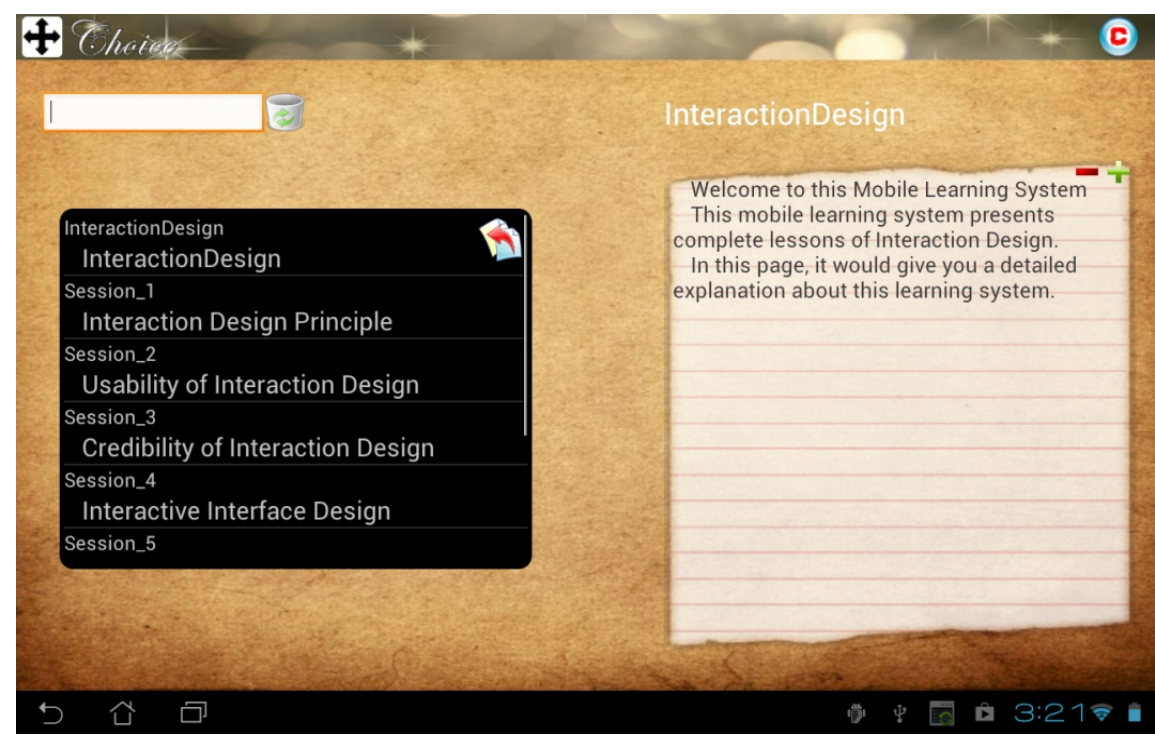

Figure 8. Serialist Version of PDLS

\section{Experiment Procedures}

Sixty-two students participated in Study 2, where a between-subjects design was used. More specifically, each student used either the Holist Version or the Serialist Version based on his/her cognitive style. The experimental procedures consisted of five stages in this study. The participants were asked to go through the pre-test to measure their initial levels of knowledge. In the next stage, all participants were instructed how to use the tools provided by the PDLS. Subsequently, they were required to interact with the PDLS via Tablet PCs. At the same time, the participants needed to complete the practical tasks with the PDLS. The time that they spent for completing the task was recorded in a log file. Then, the participants needed to take the post-test, which was used to evaluate their learning performance. Finally, the participants were provided with the questionnaire to express their perceptions for the use of the PDLS.

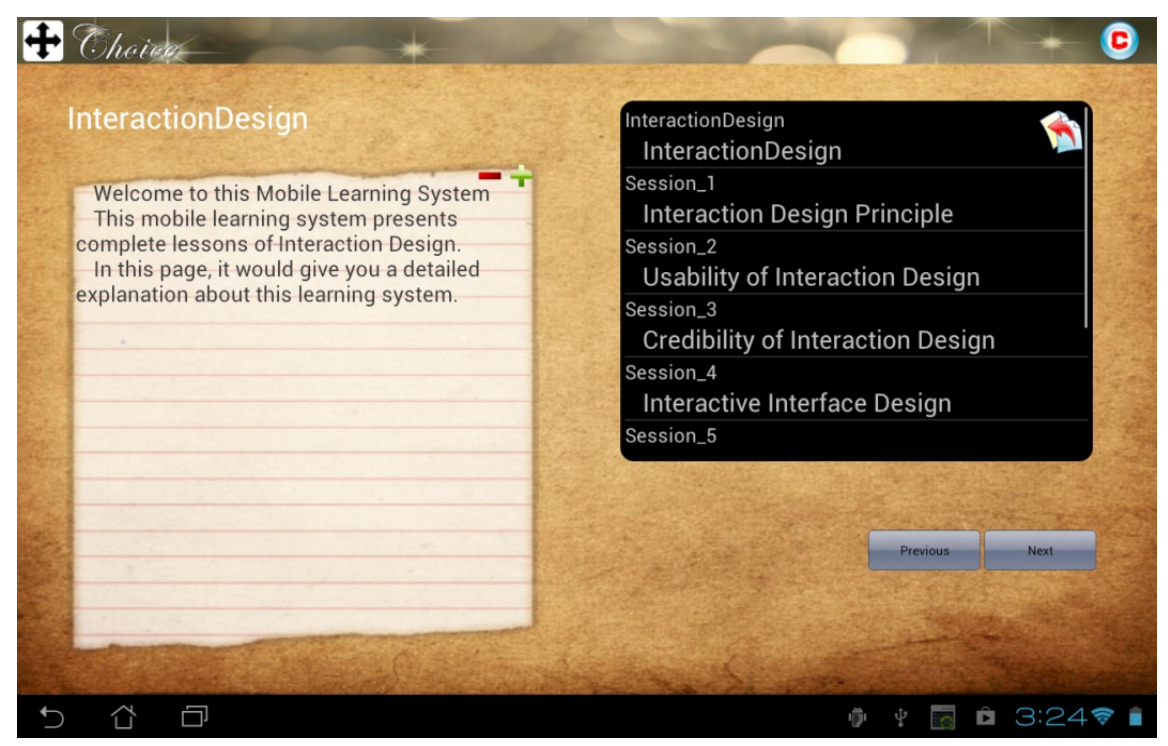


Figure 9. Holist version of PDLS

Data Analyses. To obtain a complete understanding of how Holists and Serialists reacted to the CDLS and PDLS, multiple variables were employed for data analyses in this study. The independent variables were the participants' cognitive styles and the digital learning system that the participants used, i.e., the CDLS or PDLS. The dependent variables were students' learning performance and learning perceptions. Such variables were also analyzed with the Statistical Package for the Social Sciences (SPSS) for Windows version (release 19). In addition to descriptive statistics, an independent t-test, which was suitable to identify the differences between two categories (Stephen \& Hornby, 1997), was applied to compare the participants' reactions to the PDLS and CDLS. A significance level of $\mathrm{p}<.05$ was adopted for the study.

\section{Results and Discussions}

In this section, students' reactions to the CDLS and PDLS were compared from the aspects of learning performance and learning perceptions. Regarding learning performance, task time, task score, and posttest scores were taken into account. Regarding learning perceptions, the participants' responses to the questionnaire were considered.

Learning Performance. To identify whether students with the CDLS and those with the PDLS had a similar level of prior knowledge, their pre-test scores compared. The results showed that the former (Mean=9.75, $\mathrm{SD}=3.92$ ) and the latter (Mean=9.89, $\mathrm{SD}=3.04$ ) demonstrated a similar level of prior knowledge ( $\mathrm{t}=-.18, \mathrm{p}>.05)$. As shown in Table 4, Serialists and Holists also showed a similar level of prior knowledge, regardless of the CDLS or PDLS. Students' overall learning performance is presented in Table 5. As shows in this Table, learners with the CDLS and those with the PDLS demonstrated similar post-test scores and task scores; however, the former significantly spent more time completing the tasks than the latter. The aforementioned findings suggested that the PDLS was useful for learners to complete their tasks efficiently.

Table 4

Students' Prior Knowledge

\begin{tabular}{lccccc}
\hline & & Mean & SD & t & Sig. \\
\hline \multirow{2}{*}{ CDLS } & Serialists & 9.77 & 3.17 & \multirow{2}{*}{.041} & $\mathrm{p}>.05$ \\
& Holists & 9.71 & 4.51 & & \\
\multirow{2}{*}{ PDLS } & Serialists & 9.83 & 2.79 & \multirow{2}{*}{-.96} & $\mathrm{p}>.05$ \\
& Holists & 9.94 & 3.28 & &
\end{tabular}

Table 5

Overall Learning Performance 


\begin{tabular}{cccccc}
\hline & & $\boldsymbol{M}$ & $\boldsymbol{S D}$ & $\boldsymbol{t}$ & Sig. \\
\hline \multirow{2}{*}{ Task Time } & CDLS & 75.13 & 28.41 & \multirow{2}{*}{2.80} & $\mathbf{p}<.05$ \\
& PDLS & 57.67 & 13.19 & & \\
Task Scores & CDLS & 19.77 & 5.77 & .00 & $\mathrm{p}>.05$ \\
Post-test Scores & PDLS & 19.77 & 4.43 & & $\mathrm{p}>.05$ \\
& CDLS & 14.00 & 2.73 & -.05 &
\end{tabular}

Subsequently, we moved to examine the learning performance of Serialists (Table 6) and Holists (Table 7). Serialists with the CDLS and those with the PDLS obtained similar task scores and post-test scores. However, the former significantly spent more time completing the tasks than the latter. One possible interpretation was that Serialists needed to spend more time for selecting reading/searching tools and arranging the display formats in the CDLS so they needed more time to complete the tasks. When interacting with the CDLS, Serialists not only needed to examine the subject content, but also to pay attention to selecting tools and arranging formats. Such an approach did not match with the characteristics of Serialists, who tended to do one thing at a time (Pask, 1976). Thus, they spent more time completing the tasks.

Like Serialists, Holists with the CDLS and those with the PDLS obtained similar task scores and post-test scores. Furthermore, the task time spent by Holists in the CDLS and those in the PDLS were also not significantly different. These findings suggest Holists with the CDLS and those with the PDLS performed similarly. This may be because Holists can adapt themselves to suit to different learning contexts so they feel comfortable to use various types of digital learning systems.

Table 6.

Learning Performance of Serialists

\begin{tabular}{cccccc}
\hline & & $\boldsymbol{M}$ & $\boldsymbol{S D}$ & $\boldsymbol{t}$ & Sig. \\
\hline \multirow{2}{*}{ Task Time } & CDLS & 80.15 & 32.12 & \multirow{2}{*}{2.38} & $\mathbf{p}<. \mathbf{0 5}$ \\
& PDLS & 57.67 & 5.91 & & \\
Task Scores & CDLS & 19.85 & 6.63 & .12 & $\mathrm{p}>.05$ \\
\multirow{2}{*}{ Post-test Scores } & PDLS & 19.33 & 3.82 & & \\
& CDLS & 14.29 & 3.15 & \multirow{2}{*}{.51} & $\mathrm{p}>.05$ \\
\cline { 2 - 3 } & PDLS & 13.5 & 1.98 & &
\end{tabular}

Table 7

Learning Performance of Holists

\begin{tabular}{cccccc}
\hline & & $\boldsymbol{M}$ & $\boldsymbol{S D}$ & $\boldsymbol{t}$ & $\boldsymbol{S}$ ig. \\
\hline Task Time & CDLS & 71.29 & 26.52 & 1.52 & $\mathrm{p}>.05$
\end{tabular}




\begin{tabular}{cccccc}
\hline \multirow{3}{*}{ Task Scores } & PDLS & 61.22 & 8.83 & & \\
\multirow{2}{*}{ Post-test Scores } & CDLS & 19.70 & 5.44 & -.19 & $\mathrm{p}>.05$ \\
& PDLS & 20.06 & 5.00 & & \\
& CDLS & 14.47 & 2.55 & .08 & $\mathrm{p}>.05$
\end{tabular}

Learning Perceptions. Students' thoughts are very essential (Tsai, 2014) so their responses to the questionnaire were used to measure their positive perceptions and negative attitudes. More specifically, each statement could be classed as either in favor or not in favor of the scenario. The total score for 15 favored statements was used to measure their positive perceptions while that for 15 non-favored statements was employed to identify their negative attitudes.

According to such criteria, we found that the total score of favored statements obtained from the PDLS was similar to that from the CDLS. On the other hand, the total score of non-favored statements in the CDLS was also similar to that from the PDLS. These findings show that no significant differences exist between students with the CDLS and those with the PDLS, in terms of their overall positive perceptions and negative attitudes (Table 8).

Table 8

The Overview of Learning Perceptions

\begin{tabular}{llcccc}
\hline & & Mean & SD & t & Sig. \\
\hline \multirow{2}{*}{ Positive Perceptions } & CDLS & 3.56 & 0.83 & \multirow{2}{*}{.43} & $\mathrm{p}>.05$ \\
& PDLS & 3.50 & 0.99 & & \\
\multirow{2}{*}{ Negative Attitudes } & CDLS & 2.60 & 0.79 & \multirow{2}{*}{.25} & $\mathrm{p}>.05$ \\
& PDLS & 2.51 & 1.01 & &
\end{tabular}

Regarding how Holists and Serialists reacted differently to the CDLS and PDLS, both of them perceived similarly to the CDLS and PDLS, in terms of both positive perceptions (Serialists: $t=.35, p>.05$; Holists: $\mathrm{t}=.63, \mathrm{p}>.05$ ) and negative attitudes (Serialists: $\mathrm{t}=.71, \mathrm{p}>.05$; Holists: $\mathrm{t}=.27, \mathrm{p}>.05$ ). Additionally, Holists and Serialists demonstrated similar reaction to CDLS, in terms of both positive perceptions and negative attitudes (Table 9). However, we found that Holists significantly showed more positive perceptions for the PDLS than Serialists while Serialists significantly showed more negative attitudes for the PDLS than Holists (Table 10). In brief, Holists positively perceived the PDLS while Serialists negatively perceived the PDLS.

Table 9

The Learning Perceptions for the CDLS

$\begin{array}{llll}\text { Mean } & S D & t & \text { Sig. }\end{array}$




\begin{tabular}{lccccc}
\hline \multirow{2}{*}{ Positive Perceptions } & Serialists & 3.38 & 0.80 & \multirow{2}{*}{.43} & $\mathrm{p}>.05$ \\
& Holists & 3.74 & 0.87 & & \\
Negative Attitudes & Serialists & 2.75 & 0.98 & .68 & $\mathrm{p}>.05$ \\
& Holists & 2.44 & 0.99 & &
\end{tabular}

Table 10

The Learning Perceptions for the PDLS

\begin{tabular}{lccccc}
\hline & & Mean & SD & t & Sig. \\
\hline \multirow{2}{*}{ Positive Perceptions } & Serialists & 3.01 & 0.79 & \multirow{2}{*}{2.158} & $\mathrm{p}<.05$ \\
& Holists & 3.98 & 0.78 & & \\
\multirow{2}{*}{ Negative Attitudes } & Serialists & 2.98 & 0.94 & \multirow{2}{*}{2.147} & $\mathrm{p}<.05$
\end{tabular}

Furthermore, we found that Serialists and Holists significantly showed different responses to two statements, i.e., Q26 and Q27 (Table 11). Regarding Q26, Serialists were happy with the display format. Conversely, Holists were neutral with this statement. Regarding Q27, Holists demonstrated more positive reactions if an additional tool could be provided. Conversely, Serialists were neutral with the provision of an additional tool. The results from such responses show some interesting differences between Serialists and Holists, in terms of the provision of additional tools and the arrangement of display formats. More specifically, Serialists with the PDLS paid more attention to the display formats while Holists with the PDLS were more concerned with tools provided. This may be due to the fact that Serialists learn and remember information step-by-step (Pask, 1979) so the orderliness of the display formats was important for them. On the other hand, Holists tend to explore various types of concepts to build an overall picture of the subject content (Howie, 1995). Thus, they attempted to build the whole picture of the subject content by using various tools. Accordingly, providing additional tools was beneficial for them to seek information.

Table 11

Students' Responses to Q 26 and Q27

\begin{tabular}{|c|c|c|c|c|c|}
\hline & & Mean & $S D$ & $t$ & Sig. \\
\hline Q26 & $\begin{array}{c}\text { Serialists } \\
\text { Holists }\end{array}$ & $\begin{array}{l}3.83 \\
2.83\end{array}$ & $\begin{array}{l}0.58 \\
1.20\end{array}$ & 2.67 & $\mathrm{p}<.05$ \\
\hline Q27 & $\begin{array}{c}\text { Serialists } \\
\text { Holists }\end{array}$ & $\begin{array}{l}3.17 \\
4.06\end{array}$ & $\begin{array}{l}1.03 \\
0.94\end{array}$ & -2.44 & $\mathrm{p}<.05$ \\
\hline
\end{tabular}




\section{Summary}

After analyzing the results of Study 2, we found that learners with the PDLS significantly spent less time completing the tasks than those with the CDLS. Likewise, Serialists with the PDLS significantly spent less time completing the tasks than those with the CDLS. Conversely, Holists with the PDLS and those with the CDLS spent a similar amount of time completing the tasks. On the other hand, no significant differences exist between the CDLS and PDLS, in terms of students' overall positive perceptions and negative attitudes. However, Holists significantly demonstrated more positive perceptions to the PDLS than Serialists. Conversely, Serialists significantly showed more negative attitudes to the PDLS than Holists.

\section{Conclusions}

Like each technology, which has distinct characteristics and affordances, handheld devices also have unique features (Young \& Hung, 2014). Hence, we conducted two empirical studies to examine how different cognitive style groups reacted to the CDLS and PDLS implemented in the context of handheld devices. The results from Study 1 showed that Serialists and Holists have different preferences for the selection of various tools and the arrangement of display formats. According to such results, we developed the PDLS in Study 2, the results of which indicated that Serialists with the PDLS could more efficiently complete the tasks than those with the CDLS; however, Serialists perceived the PDLS more negatively than Holists. These findings suggested that good performance that Serialists demonstrated could not make them have positive perceptions. In other words, performance was not associated with perceptions for Serialists. Therefore, both performance and perceptions need to be considered when we develop the CDLS and PDLS in the context of handheld devices.

In brief, the results from Study 1 and Study 2 suggest that cognitive styles play an important role. Thus, there is a need to be aware of cognitive styles when delivering customization and personalization. The contributions of these two studies include three aspects: theory, methodology, and applications.

Theory: This research deepens the understandings of the importance of cognitive styles by providing empirical evidence. Cognitive styles are frequently considered in the literature of individual differences but it is unknown how they affect learners' reactions to the CDLS and PDLS implemented in the context of the handheld devices. The findings of this work contribute to the knowledge of the influences of cognitive styles on their responses to customization and personalization.

Applications: Two digital learning systems were developed in this work. One was to provide customization while the other was to offer personalization. The CDLS allowed learners to adjust the layout and tools based on their preferences. The PDLS included the Holist version and Serialist version. Design approaches proposed in these two digital learning systems can also be employed to support the development of other technology-based learning tools, such as game-based learning.

Methodology: This work developed a user model to illustrate the needs of different cognitive style groups. This user model could not only help instructors develop effective instruction approaches that can 
accommodate students' individual differences, but also can work as design guidelines to support designers to develop educational resources that meet the needs of each learner.

In spite of the aforementioned contributions, several limitations still exist. Firstly, this work only used a small-scaled sample. Hence, it is recommended that future research should be undertaken with a larger sample to provide enough evidence. The other limitation is that this research only takes into account Pask's Holism/Serialism. Thus, it is necessary for further studies to consider other dimensions of cognitive styles and other human factors. Furthermore, handheld devices are limited to tablet computers so future works can consider other types of handheld devices. The results from such studies can be incorporated into those of this research to build robust user models so that the benefits of customization and personalization can be optimized in the context of handheld devices.

\section{References}

Allan, C., Carbonaro, M., \& Buck, G. (2006). A survey of personal digital assistants (PDAs) use in a middle school environment: Perceptions of teachers, parents and students. Meridian Middle School Computer Technologies Journal, 2(9).

Attewell, J. (2005). Mobile Technologies and Learning: A technology update and m-learning project summary. London: Learning and Skills Development Agency.

Chen, S. Y., \& Chang, L. (in press). The influences of cognitive styles on individual learning and collaborative learning. Innovations in Education and Teaching International.

Chen, S. Y. \& Macredie, R. (2010). Web-based interaction: A review of three important human factors. International Journal of Information Management, 30(5), 379-387.

Chen, S. Y., \& Liu, X. (2008). An integrated approach for modeling learning patterns of students in webbased instruction: A cognitive style perspective. ACM Transactions on Computer-Human Interaction, 15(1), 1-28.

Chen, S. Y., \& Macredie, R. D. (2002). Cognitive styles and hypermedia navigation: development of a learning model. Journal of the American Society for Information Science and Technology, 53(1), 315 .

Cheung, W. S., \& Hew, K. F. (2009). A review of research methodologies used in studies on mobile handheld devices in K-12 and higher education settings. Australasian Journal of Educational Technology, 25(2), 153-183.

Clewley, N., Chen, S. Y., \& Liu, X. (2010). Cognitive styles and search engine preferences: Field 
dependence/independence vs. Holism/Serialism. Journal of Documentation, 66(4), 585-603.

Clewley, N., Chen, S. Y., \& Liu, X. (2011). Mining learning preferences in web-based instruction: Holists vs. serialists. Educational Technology \& Society, 14 (4), 266-77.

Churchill, D., \& Hedberg, J. (2008). Learning object design considerations for small-screen handheld devices. Computers \& Education, 50(3), 881-893.

De Jong, K. A. (1975). Analysis of the behavior of a class of genetic adaptive systems. [Doctoral Dissertation]. The University of Michigan, Ann Arbor, MI.

Finlater, L., \& McGrenere, J. (2004). A comparison of static, adaptive, and adaptable menus. In Proceedings of CHI 2004.

Ford, N. (1985). Learning styles and strategies of postgraduate students. British Journal of Educational Technology, 16(1), 65-79.

Frias-Martinez, E., Chen, S. Y., \& Liu, X. (2009). Evaluation of a personalized digital library based on cognitive styles: Adaptivity vs. adaptability. International Journal of Information Management. 29(1), 48-56.

Frias-Martinez, E., Chen, S. Y., Macredie, R., \& Liu, X. (2007). the role of human factors in stereotyping behaviour and perception of digital library users: A robust clustering approach. User Modelling and User Adapted Interaction. 17(3), 305-337.

Gena, C., Cena, F., Vernero, F., \& Grillo, P. (2013). The evaluation of a social adaptive website for cultural events. User Modelling and User Adapted Interaction. 23(2-3), 89-137.

Howie, D. (1995). To the beat of a different drummer: The role of individual differences in ecological interface design. [Technical Report]. Cognitive Engineering Laboratory. University of Tornado, Canada.

Hsieh, T.-C., Lee, M.-C., \& Su, C.-Y. (2013). Designing and implementing a personalized remedial learning system for enhancing the programming learning. Educational Technology \& Society, 16 (4), 32-46.

Jonassen, D. H., \& Grabowski, B. L. (1993). Handbook of individual differences, learning and instruction. Hillsdale, NJ: Lawrence Erlbaum Associates.

Jonsson, I. Nass, I., \& Lee, K. (2004). Mixing personal computer and handheld interfaces and devices: effects on perceptions and attitudes. International Journal of Human-Computer Studies, 61(1), 7183.

Kay, J. (2001). Learner control. User Modeling and User-Adapted Interaction, 11(1/2), 111-127. 
Kelly, B., Nevile, L., Sloan, D., Fanou, S., Ellison, R., \& Herrod, L. (2009). From web accessibility to web adaptability. Disability and Rehability: Assistive Technology, 4 (4). 212 -226. ISSN 1748- 3115.

Kinshuk, R. (1996). Computer aided learning for entry accountancy students. [Doctoral Dissertation]. DeMontfort University, UK.

Kobsa, A., Koenemann, J., \& Pohl, W. (2001). Personalised hypermedia presentation techniques for improving customer relationships. Knowledge Engineering Review, 16(2), 111-155.

Maglio, P., Barrett, R., Campbell, C., \& Selker, T. (2000). Suitor: An attentive information system. In Proceedings of the International Conference on Intelligent User Interfaces 20oo. New Orleans, LA: ACM Press.

Mampadi, F., Chen, S. Y., Ghinea, G., \& Chen, M. P. (2011). Design of adaptive hypermedia learning systems: A cognitive style approach. Computers \& Education, 56(4), 1003-1011.

Myers, B.A. \& Beigl, M. (2003). Guest editors' introduction: Handheld computing. Computer, 36(9), 2729.

Pask, G. (1979). Final report of S.S.R.C. Research Programme HR 2708. Richmond (Surrey): System Research Ltd.

Pask, G. (1976). Styles and strategies of learning. British journal of educational psychology, 46(2), 128148.

Powell, R.R. (1997). Basic research methods for librarians (3rd ed.). Greenwich, CN: Ablex Publishing Corporation.

Riding, R. J. (1991). Cognitive styles analysis. Birmingham: Learning and Training Technology.

Riding, R., \& Rayner, S. (1998). Cognitive styles and learning strategies: Understanding style differences in learning and behavior. London: David Fulton Publishers.

Rosli, M., Ismail, I., Idrus, R. M., \& Ziden, A. A. (2010). Adoption of mobile learning among distance education students in Universiti Sains Malaysia. International Journal of Interactive Mobile Technologies (iJIM), 4(2), pp-24.

Stephen, P. \& Hornby, S. (1997). Simple statistics for library and information professionals. London: Library Association.

Tan, H., Guo, J., \& Li, Y. (2008) E-Learning recommendation system. Proceedings of International Conference on Computer Science and Software Engineering. Vol. 5, 430-433.

Teng, C. I. (2010). Customization, immersion satisfaction, and online gamer loyalty. Computers in 
Human Behavior, 26(6), 1547-1554.

Treiblmaier, H., Madlberger, M., Knotzer, N., \& Pollach, I. (2004). Evaluating personalization and customization from an ethical point of view: An empirical study. In System Sciences, 2004. Proceedings of the 37th Annual Hawaii International Conference on (pp. 10-pp). IEEE.

Tsai, C. W. (2014). A quasi-experimental study of a blended course integrated with refined web-mediated pedagogy of collaborative learning and self-regulated learning. Interactive Learning Environments, 22(6), 737-751.

Witkin, H. A., Moore, C. A., Goodenough, D. R., \& Cox, P. W. (1977). Field-dependent and fieldindependent cognitive styles and their educational implications. Review of Educational Research, 164.

Young, S. S \& Hung, H. (2014). Coping with the challenges of open online education in Chinese societies in the mobile era: NTHU OCW as a case study. The International Review of Research in Open and Distributed Learning, 15(3)

Athabasca

University

(2) $\stackrel{\oplus}{\mathrm{Ix}}$ 